\title{
Incidence and Determinants of Stillbirth amongst Parturients in Two Hospitals in Southern Nigeria
}

\author{
Lawrence O Omo-Aghoja, EA Onohwakpor, AT Adeyinka ${ }^{1}$, JA Omene ${ }^{2}$ \\ Departments of Obstetrics and Gynecology, College of Health Sciences, Delta State University, Abraka, ${ }^{~}$ Delta State University Teaching Hospital, \\ Oghara, ${ }^{2}$ Department of Paediatrics and Child Health, Niger-Delta University, Amasooma, Niger Delta, Nigeria
}

\section{A B S T R A C T}

Background: Fetal death is a major but often overlooked public health issue. Aim: Knowledge of the causes and risk factors will help in designing measures to reduce the burden of fetal death in Nigeria. Materials and Methods: A 5 year descriptive study of all fetal mortality of >28 weeks in Southern Nigeria. Relevant details were extracted from the case notes and the registers in the labor ward, maternity ward, the labor ward theater and the main theater. Statistical Analysis Used: The data was analyzed using Statistical Package for Social Scientist (SPSS PC+) and this consisted of univariate analysis and comparisons of identified relationships. Results: The total number of deliveries from 28 weeks was 25,780 and the number of parturients with fetal mortality after 28 weeks was 157 and therefore the incidence of stillbirth was $0.6 \%$ giving a mortality rate of $6.1 / 1000$ total births. However, 148 (85\%) case notes of the total fetal deaths were retrieved and formed the study sample. Socio-demographic variables such as extremes of age and parity, unbooked status, unemployment, unmarried, Isoko, Itsekiri and ljaw ethnic groups and primary level or no formal education were determinants of stillbirth. Others were maternal diabetes mellitus, malaria, hypertension, labor duration $>4 \mathrm{~h}$, instrumental or assisted vaginal delivery, gestational age at booking $>12$ weeks, low birth weight and preterm births. Conclusion: The fetal mortality (stillbirth) rate was low and the determinants were identified. Public health education, female education and socio-economic empowerment are suggested preventive measures.

KEY WORDS: Amongst parturients, determinants, fetal mortality, incidence, Southern Nigeria, stillbirth

\section{INTRODUCTION}

Fetal death is often a tragic experience for the mother, her family and the health care provider (as well). Furthermore, concern about the outcome of future pregnancies is a major but often overlooked public health issue.

Fetal death is the death prior to the complete expulsion or extraction from its mother of a product of human conception, irrespective of the duration of pregnancy and which is not an induced termination of pregnancy; the death is indicated by the fact that after such expulsion or extraction, the fetus does not breathe or show any other evidence of life such as beating of the heart, pulsation of the umbilical cord, or definite movement of voluntary muscles; heartbeats are to be distinguished from transient

\begin{tabular}{|l|l|}
\hline \multicolumn{2}{|c|}{ Access this article online } \\
\hline Quick Response Code & $\begin{array}{l}\text { Website: } \\
\text { www.jbcrs.org }\end{array}$ \\
\cline { 2 - 2 } & DOI: \\
& $* * *$ \\
\hline
\end{tabular}

cardiac contractions; respirations are to be distinguished from fleeting respiratory efforts or gasps. ${ }^{[1]}$ Fetal death is classified as early ( $<20$ weeks), intermediate ( $21-27$ weeks), or late ( $\geq 28$ weeks). ${ }^{[1]}$ Stillbirth is used interchangeably with fetal death occurring after a specified gestational age (GA); and the gestational period or fetal weight prescribed in defining stillbirth varies among different regions of the world. $^{[2,3]}$ In regions with advanced medical services, the prescribed fetal weight and GA ranges between at least 350-500 g and 20-24 weeks respectively with the specific figures depending on local legal definitions. ${ }^{[3,4]}$ In Nigeria and indeed other low resource settings with limited salvage rate of preterm fetuses and for the purposes of international comparism, a gestation age of $\geq 28$ weeks or birth weight $\geq 1000 \mathrm{~g}$ is prescribed. ${ }^{[4,5]}$ Therefore, depending on the region, the term fetal mortality rate (FMR) or stillbirth rate is the number of fetal deaths after 20 weeks, 24 weeks, or 28 weeks/1000 births within the same period. ${ }^{[5]}$

Stillbirth have been well-identified from time in history even from early biblical times ${ }^{[6]}$ and available data on stillbirth

Address for correspondence Dr. Lawrence O Omo-Aghoja, Department of Obstetrics and Gynaecology, College of Health Sciences, Delta State University, Abraka, Nigeria. E-mail: eguono_2000@yahoo.com 
suggests that the incidence of stillbirths in developing countries is about 10 times that in developed world. ${ }^{[5,7]}$ World-wide, at least 2.65 million stillbirths $(\geq 1000 \mathrm{~g}$ birth weight or $\geq 28$ weeks of gestation) were estimated in $2008 . .^{[5,8]}$ Reliable data on fetal deaths in Nigeria are scant due to under reporting and documentation. Nevertheless, hospital-based reporting serves the purpose of pointing to the adverse obstetric practice in the community concerned.

About $98 \%$ of stillbirths occur in low-income and middle-income countries and the numbers vary from 2.0/1000 total births in Finland to more than 40/1000 total births in Nigeria. ${ }^{[5,8 \mid}$ Study conducted in Jos University Teaching Hospital (2011) reported stillbirth incidence of 40.6/1000 total births; ${ }^{[9]}$ similar findings of 39.7/1000 was reported in Benin (2009). ${ }^{[10]}$ However, a lower incidence of 10.8 stillbirths/1000 births was recorded in a study conducted among only booked parturient in Southwestern Nigeria ${ }^{[11]}$ suggesting significant role antenatal care program plays in our effort to reduce the incidence of stillbirth.

Although about $25-60 \%$ of fetal deaths are not associated with any obvious risk factors or causes, various risk factors and maternal conditions have been described..$^{[8-17]}$ Knowledge of the causes and risk factors of this tragic public health challenge will help in designing preventive measures to reduce its incidence. ${ }^{[18-21]}$ It is against this backdrop that we embarked on this study with the overall goal of determining the incidence of stillbirth and the socio-demographic and clinical variables associated with fetal deaths among parturients at the Central Hospital Warri and General Hospital, Ekpan in Delta state.

\section{MATERIALS AND METHODS}

This was a 5 year retrospective descriptive study of all fetal mortality between January 2007 and December 2011. The study was conducted at the departments of Obstetrics and Gynecology of the Central Hospital, Warri and the General Hospital Ekpan. Central Hospital, Warri is a tertiary health institution, located in the oil rich city of Warri while the General Hospital Ekpan is as secondary health care facility, both in Delta State in the Niger Delta region of Nigeria. Warri is a major oil city in Delta State, Nigeria, with a population of over 300,000 people. The people of Warri are mainly the Urhobos, Itsekiris and ljaws, but other ethnic groups also live within the city. Warri is predominantly Christian, as is most of Southern Nigeria. The city is known nationwide for its unique Pidgin English. Warri Metropolis has expanded due to infrastructural development to include boundary communities of Uvwie, Udu and Okpe local government areas (LGAs) in recent years, with various road networks linking these places into one. Each of these LGAs has its own administrative structure. There is a refinery located at Ekpan, a nearby town to Warri in Uvwie LGA. Majority of international and local oil companies operating in Nigeria have their operational offices within the city of Warri. One of the nation's major sea ports is sited within the city. The inhabitants are mainly workers of the oil and gas sector, civil servants, business men and women and traders.

The obstetric unit of the hospital principally provides tertiary health care services in obstetrics and gynecology with four consultant obstetricians and 12 resident doctors at various stages of postgraduate training. The annual obstetric population of the hospital averages 7592 girls and women with an annual delivery rate of about 5000 (65.86\% delivery rate). Antenatal care and delivery services are rendered free in these hospitals under the sponsorship of the state government free maternal care program. The study population included all parturients (booked and unbooked) who were managed within the study period in this center. Those parturients with fetuses that suffered mortality and whose case notes were retrieved with complete or adequate documentation were recruited into the study and these constituted the sample size. And those whose case notes could not be retrieved, or those retrieved with inadequate or incomplete documentation were excluded from the study. Stillbirth rate in this study was calculated using 28 weeks and it was based on the ability and capacity of the neonatal care unit to salvage fetuses of this gestational and beyond.

The names and hospital numbers of parturients who suffered fetal mortality who were seen and managed within the period under review were retrieved from the records department. Relevant details were then extracted from the registers in the labor ward, maternity ward, the labor ward theater and the main theatre. In addition their case notes from the medical records department were used as the main source document. The clinicodemographic parameters of parturients were obtained using a study proforma or data sheet designed for this purpose. The study proforma was in four parts. The first part solicited information on the relevant socio-demographic characteristics of parturients which included maternal age, parity, educational level, marital status, occupation, tribe and GA, booking status, religious sect, smoking and drinking status. The second part probed the clinical parameters and medical history of the parturients which included maternal malaria, urinary tract infection (UTI), anemia, diabetes mellitus, antepartum hemorrhage (APH) and hypertension. The third part of it was used to extract the information on duration of labor and mode of delivery. The fourth part was used to elicit information on obstetric outcomes (maternal and fetal). For the purpose of this study the age of fetal viability was taken as 28 weeks. 
Permission was sought from the management of central hospital to allow the researchers access the case notes and hospital data for purpose of this study. Ethical clearance was obtained from the Health Research and Ethnics Committee of Central Hospital, Warri.

The limitations which were envisaged in this study included difficulty with obtaining the case notes of the parturients from the records department and for those that are retrieved the documentation may be poor or incomplete. The potential impact of these limitations were mitigated by the multiple sources from which details of the parturients were accessed and well over $80 \%$ of the parturients had their case note retrieved with adequate documentation.

\section{Statistical analysis}

The completed data collection sheets (proforma) were collated, coded and entered into the computer using Statistical Package for Social Scientist (SPSS PC+, SPSS Inc., Chicago Ill, USA). The data was analyzed using the same Statistical Package for Social Scientist (SPSS PC+) and this consisted of univariate analysis and comparisons of identified relationships. Tests of statistical significance were based on 95\% confidence interval using Student's $t$-test or Chi-square test with Yates or Fischer Exact correction where applicable.

\section{RESULTS}

The total number of deliveries (TND) within the study period was 26,094 and the total number of parturients with fetal mortality was 175 . However, the TND from 28 weeks within the study period was 25,780 , the total number of parturients with fetal mortality after 28 weeks was 157 , but the total number of parturients with fetal mortality from 28 weeks whose case notes were retrieved was 148 giving a FMR of $0.6 \%$ i.e. $6.1 / 1000$ total births. The overall results from the analysis of the data are presented in Tables 1-7.

The socio-demographic variables and the FMR calculated per each of the socio-demographic variable are presented in Table 1 . The mean age of the parturients was 29.3 years (5.7). The age range was $17-44$ years with FMR that gets progressively higher at GA greater than 30 years, being $11.7 / 1000$ at $30-34$ years and 19.1/1000 at $>35$ years. The observed difference was statistically significant $(P<0.01)$. The majority $(79.7 \%)$ of the parturients were multiparous (para 1-4) and the FMR was highest in the nulliparous population (23/1000) and this was closely followed by the grand-multiparous parturients with a FMR of $10 / 1000$. The difference is statistically significant $(P=0.001)$. There were more booked patients (66.2\% [98/148]) compared with the unbooked patients $(33.8 \%$ [50/148]).
The FMR was about 4-fold higher amongst the unbooked population (17/1000 compared with 4/1000 in the booked, $P<0.01)$. Among the Urhobo ethnic group constituted the

\begin{tabular}{|c|c|c|c|c|c|c|}
\hline \multicolumn{7}{|c|}{ Table 1: Socio-demographic profile } \\
\hline Parameter & Frequency & Percentage & TND & PNMR & $\chi^{2}$ & $P$ value \\
\hline \multicolumn{7}{|l|}{ Age (years) } \\
\hline $15-19$ & 5 & 3.4 & 284 & $3 \cdot 5 / 1000$ & $9.657 * *$ & $<0.01$ \\
\hline $20-24$ & 24 & 16.2 & 7942 & $0.12 / 1000$ & & \\
\hline $25-29$ & 48 & 32.4 & 14114 & $0.07 / 1000$ & & \\
\hline $30-34$ & 39 & 26.4 & 2270 & $11.72 / 1000$ & & \\
\hline $\begin{array}{l}>35 \\
\text { Age mean }=29.3 \\
(5 \cdot 7), \\
\text { range }=17-44\end{array}$ & 32 & 21.6 & 1134 & $19.05 / 1000$ & & \\
\hline \multicolumn{7}{|l|}{ Parity } \\
\hline 0 & 17 & 11.5 & 749 & $23 / 1000$ & $13.632 * * *$ & 0.001 \\
\hline $1-4$ & 118 & 79.7 & 24,053 & $5 / 1000$ & & \\
\hline$\geq 5$ & 13 & 8.8 & 1292 & $10 / 1000$ & & \\
\hline \multicolumn{7}{|l|}{ Booking status } \\
\hline Booked & 98 & 66.2 & 23,156 & $4 / 1000$ & $8.048 * *$ & $<0.01$ \\
\hline Unbooked & 50 & 33.8 & 2938 & $17 / 1000$ & & \\
\hline \multicolumn{7}{|l|}{$\begin{array}{l}\text { Mothers } \\
\text { occupation }\end{array}$} \\
\hline Self employed & 84 & 56.8 & 17,156 & $5 / 1000$ & $20.689 * * *$ & $<0.001$ \\
\hline Civil servant & 28 & 18.9 & 6723 & $4 / 1000$ & & \\
\hline House wife & 18 & 12.2 & 1387 & $13 / 1000$ & & \\
\hline Student & 18 & 12.2 & 793 & $23 / 1000$ & & \\
\hline \multicolumn{7}{|l|}{ Marital status } \\
\hline Married & 146 & 98.6 & 25,920 & $4 / 1000$ & $4.00 *$ & 0.05 \\
\hline Single & 2 & 1.4 & 174 & $12 / 1000$ & & \\
\hline \multicolumn{7}{|l|}{ Religion } \\
\hline Christianity & 143 & 96.6 & 25,391 & $7 / 1000$ & 0.077 & 0.78 \\
\hline Islam & 5 & 3.4 & 703 & $6 / 1000$ & & \\
\hline \multicolumn{7}{|l|}{ Ethnicity } \\
\hline Urhobo & 72 & 48.6 & 14,166 & $5 / 1000$ & $9.282 *$ & 0.03 \\
\hline Isoko & 9 & 6.1 & 530 & $17 / 1000$ & & \\
\hline Ijaw & 5 & 3.4 & 221 & $23 / 1000$ & & \\
\hline Itsekiri & 4 & 2.7 & 141 & $28 / 1000$ & & \\
\hline Others & 58 & 39.2 & 10895 & $5 / 1000$ & & \\
\hline \multicolumn{7}{|l|}{$\begin{array}{l}\text { Educational } \\
\text { status }\end{array}$} \\
\hline None & 3 & 2.0 & 126 & $21 / 1000$ & $19.167^{* * *}$ & $<0.001$ \\
\hline Primary & 33 & 22.3 & 1886 & $18 / 1000$ & & \\
\hline Secondary & 70 & 47.3 & 12990 & $5.4 / 1000$ & & \\
\hline Tertiary & 42 & 28.4 & 11,092 & $3.7 / 1000$ & & \\
\hline
\end{tabular}

${ }^{*} P<0.01, * * P<0.001 ; * * * P<0.0001$. PNMR - Perinatal mortality rate; TND - Total number of deliveries

\begin{tabular}{lc|c|c|c|c|c}
\hline \multicolumn{7}{c}{ Table 2: Maternal morbidities } \\
\hline Parameter & $\mathrm{N}$ & Percentage & TND* & PNMR & $\chi^{2}$ & P value \\
\hline $\begin{array}{l}\text { Malaria } \\
\text { Yes }\end{array}$ & 3 & 2 & 131 & $23 / 1000$ & 11.6 & 0.001 \\
$\quad$ No & 145 & 98 & 26,703 & $5 / 1000$ & & \\
UTI \\
$\quad$ Yes \\
$\quad$ No
\end{tabular}

UTI: Urinary tract infection, TND - Total number of deliveries; APH - Antepartum hemorrhage PNMR - Perinatal mortality rate 


\begin{tabular}{|c|c|c|c|c|c|c|}
\hline \multicolumn{7}{|c|}{ Table 3: Duration of labor and mode of delivery } \\
\hline Parameter & Frequency $(N)$ & Percentage & TND & PNMR & $\chi^{2}$ & $P$ value \\
\hline \multicolumn{7}{|l|}{ Duration of labor (h) } \\
\hline$<4$ & 17 & 11.5 & 11,899 & $1.4 / 1000$ & 8.333 & 0.02 \\
\hline $4-8$ & 30 & 20.3 & 5297 & $6.0 / 1000$ & & \\
\hline$>8$ & 101 & 68.2 & 8898 & $11.4 / 1000$ & & \\
\hline \multicolumn{7}{|l|}{ Mode of delivery } \\
\hline SVD & 112 & 75.7 & 20,814 & $5 / 1000$ & 1.167 & 0.56 \\
\hline CS & 20 & 13.5 & 4045 & $5 / 1000$ & & \\
\hline Assisted vaginal del & 9 & 6.1 & 583 & $15 / 1000$ & & \\
\hline $\begin{array}{l}\text { Instrumental } \\
\text { delivery }\end{array}$ & 7 & 5.1 & 652 & $11 / 1000$ & & \\
\hline
\end{tabular}

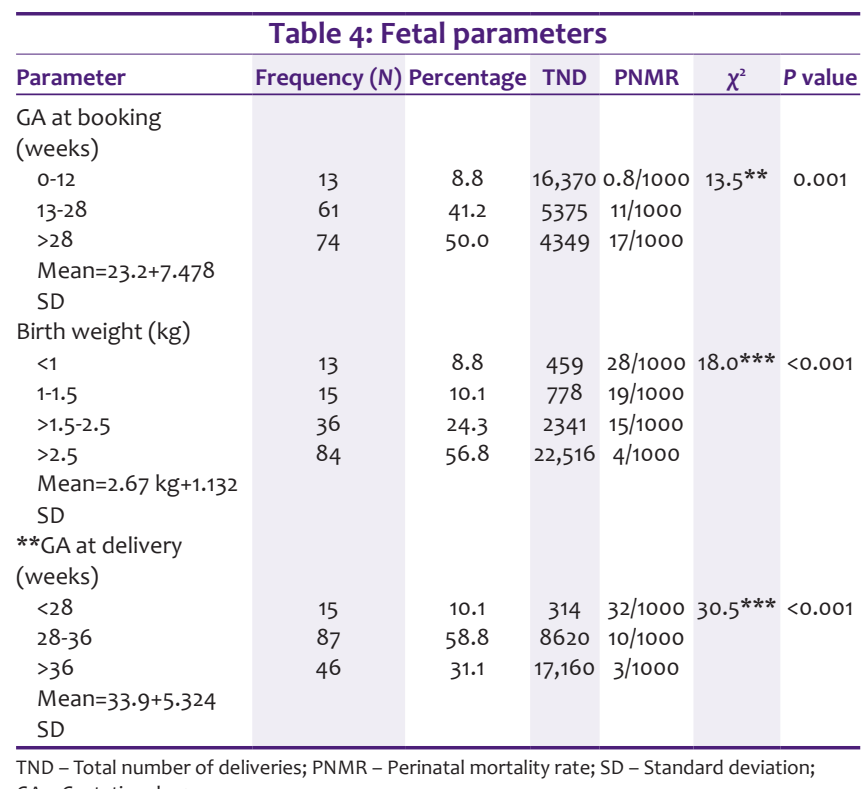

GA - Gestational age

majority (48.6\% [72/148]) of the parturients while the Itsekiri ethnic group accounted for only $(2.7 \%$ [4/148]). The FMR was 28/1000 and 23/1000 amongst the Itsekiris and Ijaws respectively. Secondary level of education was the most common (47.3\% [70/148]) educational level attained and the FMR was highest (21/1000) in the non-educated and followed closely by those with primary level of education 18/1000).

The maternal morbidities giving birth to stillbirths are presented in Table 2. Only 2.0\% (3/148) had malaria and the FMR was about 5 -fold higher than in those who did not have malaria (23/1000 compared with 5/1000). The difference was statistically significant $(P=0.001)$. Similarly, parturients who had UTI, anemia, diabetes mellitus and hypertension had FMR much more greater than in parturients who did not have these morbidities. Indeed parturients with diabetes mellitus had FMR as high as 65/1000 when compared with those with no diabetes who had FMR of 6/1000 the difference being statistically significant $(P<0.001)$.

The duration of labor and mode of delivery are presented in Table 3. Majority (68.2\% [101/148]) of the parturients had

\begin{tabular}{|c|c|c|c|c|c|c|c|}
\hline \multirow[t]{2}{*}{ Parameter } & \multicolumn{5}{|c|}{ Educational level attained } & \multirow[t]{2}{*}{$\chi^{2}$} & \multirow[t]{2}{*}{$P$ value } \\
\hline & None & Primary & Secondary & Tertiary & Total & & \\
\hline \multicolumn{8}{|l|}{ Ethnicity } \\
\hline Urhobo & $1(0.8)$ & $23(17.7)$ & $65(50)$ & $41(31.5)$ & 130 & 30.2 & $<0.001$ \\
\hline Isoko & $0(0.0)$ & $6(66.7)$ & $2(22.2)$ & $1(11.1)$ & 9 & & \\
\hline ljaw & $0(0.0)$ & $4(80)$ & $1(20)$ & $0(0.0)$ & 5 & & \\
\hline Itsekiri & $2(50)$ & $0(0.0)$ & $2(50)$ & $0(0.0)$ & 4 & & \\
\hline \multicolumn{8}{|l|}{ Booking status } \\
\hline Booked & $0(0.0)$ & $3(10.0)$ & $56(80.0)$ & $39(92.9)$ & 98 & 73.7 & $<0.001$ \\
\hline Unbooked & $3(100.0)$ & $30(90.0)$ & $14(20.0)$ & $3(7.1)$ & 50 & & \\
\hline \multicolumn{8}{|l|}{ GA at delivery } \\
\hline$<28$ & $2(6.5)$ & $16(51.6)$ & $12(38.7)$ & $1(3.2)$ & 31 & 36.3 & $<0.001$ \\
\hline $28-36$ & $1(2.2)$ & $10(21.7)$ & $24(52.2)$ & $11(23.9)$ & 46 & & \\
\hline$>37$ & $0(0.0)$ & $6(11.3)$ & $18(34.0)$ & $29(54.7)$ & 53 & & \\
\hline
\end{tabular}

GA - Gestational age

\begin{tabular}{|c|c|c|c|c|c|c|}
\hline \multirow[t]{2}{*}{ Parameter } & \multicolumn{4}{|c|}{ Ethnicity N (\%) } & \multirow[t]{2}{*}{$\chi^{2}$} & \multirow[t]{2}{*}{$P$ value } \\
\hline & Urhobo & Isoko & ljaw & Itsekiri & & \\
\hline \multicolumn{7}{|c|}{ Booking status } \\
\hline Booked & $45(62.5)$ & $3(33.3)$ & $1(20)$ & $3(75)$ & 6.0 & 0.09 \\
\hline Unbooked & $27(37.5)$ & $6(66.7)$ & $4(80)$ & $1(25)$ & & \\
\hline \multicolumn{7}{|c|}{ Birth weight (kg) } \\
\hline$<1$ & $7(9.7)$ & $2(22.2)$ & $1(20)$ & $2(50)$ & 30.5 & $<0.001$ \\
\hline $1-<1.5$ & $3(4.2)$ & $2(22.2)$ & $4(80)$ & $1(25)$ & & \\
\hline $1.5-<2.5$ & $14(19.4)$ & $2(22.2)$ & $0(0.0)$ & $1(25)$ & & \\
\hline$>2.5$ & $48(66.7)$ & $3(33.4)$ & $0(0.0)$ & $0(0)$ & & \\
\hline
\end{tabular}

\begin{tabular}{|c|c|c|c|c|c|}
\hline \multirow[t]{2}{*}{ Parameters } & \multicolumn{3}{|c|}{ GA at delivery (weeks) N (\%) } & \multirow[t]{2}{*}{$\chi^{2}$} & \multirow[t]{2}{*}{$P$ value } \\
\hline & $<28$ & $28-36$ & $>37$ & & \\
\hline \multicolumn{6}{|c|}{ Booking status } \\
\hline Booked & $5(18.5)$ & $57(67.9)$ & $29(78.4)$ & 27.0 & $<0.001$ \\
\hline Unbooked & $22(81.5)$ & $27(32.1)$ & $8(21.6)$ & & \\
\hline Total & $27(100)$ & $84(100)$ & $37(100)$ & & \\
\hline
\end{tabular}

labor duration greater than $8 \mathrm{~h}$ and the FMR was highest in this category (11.4/1000), which is 2-fold and about 10 -fold higher in those whose labor duration had lasted $4-8 \mathrm{~h}$ and $<4 \mathrm{~h}$ respectively. The difference was statistically significant $(P=0.02)$. Majority $(75.7 \%[112 / 148])$ of the parturients had spontaneous vaginal delivery (SVD). High FMR of 15/1000 was observed in fetuses delivered by instruments (5.1).

The mean GA at booking was 23.2 weeks (7.5). The later the GA at booking the higher the FMR [Table 4]. 50\% (74/148) of the parturients booked at $>28$ weeks with a FMR of $17 / 1000$ while those that booked early in the first trimester had a FMR as low as $0.8 / 1000$, the difference being statistically significant $(P=0.001)$. The lower the birth weight and $\mathrm{GA}$ at delivery, the higher the FMR and the observed differences were statistically significant $(P<0.001$ and $P<0.001$ respectively).

The associations between educational level and selected clinico-socio-demographic parameters are as 
presented in Table 5. The difference was statistically significant $(P<0.001)$. The parturients with higher educational status were more likely to book early and vice versa. Those with primary or less levels of education had $90-100 \%(30 / 33-3 / 3)$ of them unbooked compared with only $10 \%(3 / 33)$ of booked patients with these low levels of education, the difference being statistically significant $(P<0.001)$. Similarly, the lower levels of education the higher frequency of preterm births and those with tertiary level of education had more of term deliveries. The difference was statistically significant $(P<0.001)$.

Over two-thirds (62.5\% [45/72]) of the baby of Urhobos mothers were of normal birth weight while all $(100 \%$ [9/9]) babies born to Itsekiris mothers and Ijaw mothers are of low birth weight [Table 6]. The difference was statistically significant $(P<0.001)$.

Booked parturients were more likely to deliver at term $(78.4 \%$ [29/37]) when compared with the unbooked parturients with only $21.6 \%(8 / 37)$ term delivery [Table 7]. The difference was statistically significant $(P<0.001)$.

\section{DISCUSSION}

Fetal mortality is a major but often overlooked public health issue. This study was conceptualized with the overall goal of determining the incidence of stillbirth and the socio-demographic and clinical variables associated with fetal deaths among parturients at the Central Hospital Warri in Delta state in Southern Nigeria. Because we believed that the findings of this study may be useful for designing appropriate interventions that will improve our obstetric practices and reduce the enormity of the burden of fetal death in Nigeria. The incidence of fetal mortality from 28 weeks or Stillbirth was $0.6 \%$, giving a mortality rate (stillbirth rate) of $6.1 / 1000$ total births. This is significantly low compared with previous reports ${ }^{[9,21-23]}$ from Nigeria and other low resource settings, but compares favorably with figures from developed nations $\mathrm{s}^{[7]}$ and approximates the figure recorded amongst booked parturients in southwestern Nigeria. ${ }^{[1]}$ The exact reason for this observed pattern of low incidence of fetal mortality and indeed an overall FMR as low as this is uncertain. But we hypothesize, that this may be due to the positive effect of the "free maternal" health care program of the state government that was introduced in 2007 which affords pregnant women free access to antenatal care, labor and delivery care as well as postnatal care. However, further studies in particular a prospective study on fetal death is highly advocated for as this may unearth other factors that may be contributing to low FMR.

The FMR is higher at the extremes of reproductive age when compared with those within the age bracket of 20-29 years.
It is much higher in those above 35 years and at this age they are likely to be grand-multiparous and may also have chronic medical disorders complicating the pregnancy with higher propensity (as shown here) for high fetal mortality and other adverse outcomes of pregnancy. ${ }^{[24-27]}$ Though we did not evaluate in this study the reasons as to why FMR is higher in mothers less than 20 years, earlier reports have adduced the fact that at this age there is high incidence of pregnancy induced hypertension, abruption placenta ${ }^{[9]}$ and the fact most of these patients are single, pregnancies are usually unwanted, there is high incidence of malaria and anemia. That extremes of reproductive age are associated with higher rates of fetal death has earlier been reported by other researchers. ${ }^{[9]}$ Extremes of parity were associated with higher rates of fetal mortality, with nulliparous parturients having stillbirth rate higher than others. The finding that FMR is high in the grand-multiparous parturients compares favorably with reports from other centers across the country and beyond, ${ }^{[22,28,29]}$ while the higher rate of fetal mortality associated with nulliparous parturients is a unique finding of this study as previous report shows a low FMR in this category. ${ }^{[22,28,29]}$ Marital status was also shown to be strongly correlated with the risk of fetal death with higher stillbirth rates in single mothers who are most likely to be less than 20 years of age. Being married is associated with the effect of better socio-economic support from the husband. Booking status is another socio-demographic variable that affects the FMR, with the unbooked parturients having a higher FMR and this is consistent with the findings of earlier researchers on this subject matter. ${ }^{[9]}$ And it has been consistently demonstrated that the non-utilization of antenatal care is associated with higher rates of fetal mortality. ${ }^{[28,30-32]}$ Like in previous reports, ${ }^{[9,23]}$ educational level was directly correlated with booking status. The higher the educational status the more likely the parturients were to book for antenatal care. Existing evidence supports the fact that overall health seeking behavior of the more educated is much better than those of parturients with low levels of education or no formal education. ${ }^{[23,33,34]}$ This therefore explains the reason as to why FMR is lowest amongst parturients with higher level of education in this study. Education tends to minimize the challenges of low socio-economic status and lack of knowledge amongst the female folks. ${ }^{\mid 9,23]}$ Socio-economic impact is further buttressed by the finding that the unemployed (students and fulltime house wives) had higher rates of fetal mortality in this study.

Hypertensive disorders of pregnancy were the most common causes of fetal mortality in this study. This was at variance with reports of other studies in which abruptio placentae was found as the most common cause of stillbirth. ${ }^{[22,35,36]}$ $\mathrm{APH}$, malaria, anemia, diabetes mellitus and UTI were other causes of fetal mortality identified with APH ranking next to hypertensive disorders. 
Duration of labor less than $4 \mathrm{~h}$ is shown to be protective against fetal mortality, with the risk of fetal mortality increasing with labor duration great than $4 \mathrm{~h}$ and much more significantly increased with duration greater than $8 \mathrm{~h}$. Other authors have demonstrated that prolonged labor was a leading and frequent cause of fetal death. ${ }^{[37,38]}$ Similar to findings of previous studies, SVD and cesarean are less associated with fetal death whereas assisted vaginal delivery and instrumental vaginal delivery were significantly more associated with fetal deaths. This compares favorably with reports of studies from Zimbabwe and Jos in North central Nigeria. ${ }^{[9,21]}$

GA at booking is another factor that is directly correlated with the impact of booking on the risk of fetal death. Even though booking has been shown to confer protection on fetal survival, the potential benefit is affected by the gestation age at booking. This is similar to findings by other authors. ${ }^{[3,40]}$ Birth weight and GA at delivery were other factors found in this study to be associated with the risk of fetal death. Low birth weight babies were significantly more likely to suffer fetal death and risk being highest with the extremely low birth weight babies. This compares favorably with findings of earlier studies. ${ }^{[9]}$

Ethnicity seems to have been associated with the risk of fetal mortality in this study. The Itsekiris and ljaws were significantly more associated with the risk of fetal death, while the Urhobo's were least associated. Analysis of the data clearly showed that this finding operates through the interplay of educational and booking status of the parturients.

In summary, the FMR was low within the study period. Extremes of age, extremes of parity, unbooked status, unemployed, being single, being of the Isoko, Itsekiri and Ijaw ethnic group and primary level or no formal education of the parturients were socio-demographic determinants of high FMRs. Also associated with high FMRs were clinical and obstetric factors such as maternal diabetes mellitus, malaria and hypertension, increasing duration of labor usually greater than $4 \mathrm{~h}$, instrumental and or assisted vaginal delivery, GA at booking $>12$ weeks, low birth weight and preterm births. The ethnic variability, the booking status and GA at delivery were strongly correlated with the educational status of the parturients. The ethnic groups with high FMRs were more likely to be unbooked and had low birth weight deliveries. We therefore advocate that there is the need for public health education and enlightenment activities with wide outreach to sensitize the citizenry on the importance of early booking and antenatal care, the most appropriate age for reproduction and common maternal morbidities associated with high fetal mortality and therefore the need for good health seeking behavior in this regard.
We also recommend that female education and women socio-economic empowerment with relevant job placement for women are given priority.

\section{REFERENCES}

1. Barfield WD, Committee on Fetus and Newborn. Standard terminology for fetal, infant, and perinatal deaths. Pediatrics 2011;128:177-81.

2. Joseph KS, Liu S, Rouleau J, Lisonkova S, Hutcheon JA, Sauve R, et al. Influence of definition based versus pragmatic birth registration on international comparisons of perinatal and infant mortality: Population based retrospective study. BMJ 2012;344:e746.

3. Kowaleski J. Centre For Disease Control and Prevention's National Centre For Health Statistics and Reporting. State Requirement For Live Birth, Fetal Deaths and Induced termination of Pregnancy. 1997 Revision; 1997.

4. Stillbirths. Maternal, newborn, child and adolescence. Data statistics and epidemiology; WHO. Available from: http:/www.who.int/ maternal_child_adolescent/epidemiology/stillbirth/en/. [Last cited on 2014 Jan 07].

5. Macdorman MF, Kirmeyer S. The challenge of fetal mortality. NCHS Data Brief 2009;16:1-8.

6. The Holy Bible. New International Version. Numbers Ch. 12. Verse 12. Colorado: International Bible Society, Colorado Springs; 1984.

7. McClure EM, Nalubamba-Phiri M, Goldenberg RL. Stillbirth in developing countries. Int J Gynaecol Obstet 2006;94:82-90.

8. Lawn JE, Blencowe H, Pattinson R, Cousens S, Kumar R, Ibiebele I, et al. Stillbirths: Where? When? Why? How to make the data count? Lancet 2011;377:1448-63.

9. Mutihir JT, Eka PO. Stillbirths at the Jos University Teaching Hospital: Incidence, risk, and etiological factors. Niger J Clin Pract 2011;14:14-8.

10. Onyiriuka AN. Analysis of stillbirths in a Nigerian mission hospital. Nig QJ Hosp Med 2009;19:27-31.

11. Oladapo OT, Adekanle DA, Durojaiye BO. Maternal risk factors associated with fetal death during antenatal care in low-resource tertiary hospitals. Aust N Z J Obstet Gynaecol 2007;47:383-8.

12. Lindsey JL, Smith CV. Evaluation of fetal death. Available from: http://www.emedicine.medscape.com. [2012 Dec 12]. [Last cited on 2013 May 16].

13. Ouyang F, Zhang J, Betrán AP, Yang Z, Souza JP, Merialdi M. Recurrence of adverse perinatal outcomes in developing countries. Bull World Health Organ 2013;91:357-67.

14. Olusanya BO, Afe AJ, Solanke OA. Are risk factors for stillbirths in low-income countries associated with sensorineural hearing loss in survivors? J Matern Fetal Neonatal Med 2009;22:576-83.

15. Chibber R. Unexplained antepartum fetal deaths: What are the determinants? Arch Gynecol Obstet 2005;271:286-91.

16. Huang DY, Usher RH, Kramer MS, Yang H, Morin L, Fretts RC. Determinants of unexplained antepartum fetal deaths. Obstet Gynecol 2000;95:215-21.

17. Kumar MR, Bhat BV, Oumachigui A. Perinatal mortality trends in a referral hospital. Indian J Pediatr 1996;63:357-61.

18. Kambarami RA. Levels and risk factors for mortality in infants with birth weights between 500 and 1,800 grams in a developing country: A hospital based study. Cent Afr J Med 2002;48:133-6.

19. Wessel H, Cnattingius S, Bergstrom S, Dupret A, Reitmaier P. Maternal risk factors for preterm birth and low birthweight in Cape Verde. Acta Obstet Gynecol Scand 1996;75:360-6.

20. Ibeziako NS. Perinatal and neonatal mortalities. In: Azubuike JC, Nkangineme KE, editors. Pediatrics and Child Health in a Tropical Region. $1^{\text {st }}$ ed. Owerri: African Educational Services; 2007. p. 160-2.

21. Feresu SA, Harlow SD, Welch K, Gillespie BW. Incidence of stillbirth and perinatal mortality and their associated factors among women delivering at Harare Maternity Hospital, Zimbabwe: A cross-sectional retrospective analysis. BMC Pregnancy Childbirth 2005;5:9. 
22. Kuti O, Owolabi AT, Orji EO, Ogunloba IO. Antepartum fetal death in a Nigerian teaching hospital: Etiology and risk factors. Trop J Obstet Gynecol 2003;20:134-6.

23. Harrison KA. Child-bearing, health and social priorities: A survey of 22774 consecutive hospital births in Zaria, Northern Nigeria. $\mathrm{Br} \mathrm{J}$ Obstet Gynaecol 1985;92 Suppl 5:1-119.

24. Bateman BT, Simpson LL. Higher rate of stillbirth at the extremes of reproductive age: A large nationwide sample of deliveries in the United States. Am J Obstet Gynecol 2006;194:840-5.

25. Reddy UM, Ko CW, Willinger M. Maternal age and the risk of stillbirth throughout pregnancy in the United States. Am J Obstet Gynecol 2006;195:764-70.

26. Hoffman MC, Jeffers S, Carter J, Duthely L, Cotter A, González-Quintero VH. Pregnancy at or beyond age 40 years is associated with an increased risk of fetal death and other adverse outcomes. Am J Obstet Gynecol 2007;196:e11-3.

27. Aliyu MH, Salihu HM, Keith LG, Ehiri JE, Islam MA, Jolly PE. Extreme parity and the risk of stillbirth. Obstet Gynecol 2005;106:446-53.

28. Conde-Agudelo A, Belizán JM, Díaz-Rossello JL. Epidemiology of fetal death in Latin America. Acta Obstet Gynecol Scand 2000;79:371-8.

29. Osman NB, Challis K, Cotiro M, Nordahl G, Bergström S. Perinatal outcome in an obstetric cohort of Mozambican women. J Trop Pediatr 2001;47:30-8.

30. Axemo P, Liljestrand J, Bergström S, Gebre-Medhin M. Aetiology of late fetal death in Maputo. Gynecol Obstet Invest 1995;39:103-9.

31. Fawcus SR, Crowther CA, Van Baelen P, Marumahoko J. Booked and unbooked mothers delivering at Harare Maternity Hospital, Zimbabwe: A comparison of maternal characteristics and foetal outcome. Cent Afr J Med 1992;38:402-8.

32. Galvan J, Woelk GB, Mahomed K, Wagner N, Mudzamiri S, Williams MA.
Prenatal care utilization and foetal outcomes at Harare Maternity Hospital, Zimbabwe. Cent Afr J Med 2001;47:87-92.

33. Shaikh BT, Hatcher J. Health seeking behaviour and health service utilization in Pakistan: Challenging the policy makers. J Public Health (Oxf) 2005;27:49-54.

34. Ghosh N, Chakrabarti I, Chakraborty M, Biswas R. Factors affecting the healthcare-seeking behavior of mothers regarding their children in a rural community of Darjeeling district, West Bengal. Int J Med Public Health 2013;3:12-6.

35. Incerpi MH, Miller DA, Samadi R, Settlage RH, Goodwin TM. Stillbirth evaluation: What tests are needed? Am J Obstet Gynecol 1998; 178:1121-5.

36. Onderoğlu L, Tuncer ZS. The clinical predictors of intrauterine fetal death. Turk J Pediatr 1998;40:543-7.

37. van Roosmalen J. Perinatal mortality in rural Tanzania. Br J Obstet Gynaecol 1989;96:827-34.

38. Kumud, Rana AK, Chopra S. Effect of upright positions on the duration of first stage of labor among nulliparous mothers. Nurs Midwifery Res J 2013;9:10-20.

39. Zhang J, Cai WW, Chen H. Perinatal mortality in Shanghai: 1986-1987. Int J Epidemiol 1991;20:958-63.

40. Berge LN, Rasmussen S, Dahl LB. Evaluation of fetal and neonatal mortality at the University Hospital of Tromsø, Norway, from 1976 to 1989. Acta Obstet Gynecol Scand 1991;70:275-82.

How to cite this article:**

Source of Support: Nil, Conflict of Interest: None declared 